\title{
SÊNECA E PAULO FREIRE: leitura como equipagem contra a stultitia contemporânea
}

Maria Alice Gouvêa Campesato

Resumo

Este artigo, que resulta do recorte de uma pesquisa arquegenealógica que investigou a aula desde a tradição greco-romana às práticas pedagógicas inovadoras, busca refletir sobre a educação na Contemporaneidade, a partir do ferramental analítico foucaultiano da leitura como técnica de si. Para tal, aproxima a leitura como exercício espiritual praticada pelo estóico Sêneca e a leitura de mundo perspectivada pelo educador brasileiro Paulo Freire, no ano em que se celebra o centenário de seu nascimento. Essa aproximação se abre como uma possibilidade de enfrentamento às formas de vida atuais pautadas pela aceleração, fragmentação, e, recentemente, por ondas conservadoras e necrófilas, em que a opinião toma o lugar da ciência e a palavra perde sua potência e seu valor. A leitura demorada e atenta, portanto, vem a se constituir como uma forma de (re)existência, criando uma equipagem contra a stultitia contemporânea, para que se possa pensar outros modos de existência e outros mundos possíveis.

Palavras-chave: negacionismo; conservadorismo; educação.

SENECA AND PAULO FREIRE: reading as equipment against contemporary stultitia

\begin{abstract}
This article, which results from the excerpt of an archegenealogical research that investigated the class from the Greco-Roman tradition to innovative pedagogical practices, seeks to reflect on education in contemporary times, based on Foucault's analytical tools of reading as a technique of the self. To this end, it brings together reading as a spiritual exercise practiced by the stoic Seneca and the reading of the world envisaged by the Brazilian educator Paulo Freire, in the year that celebrates the centenary of his birth. This approximation opens up as a possibility of confronting current forms of life based on acceleration, fragmentation, and, recently, on conservative and necropolitics waves, in which opinion takes the place of science and the word loses its power and value.The lengthy and attentive reading, therefore, comes to be constituted as a form of (re)existence, creating an equipment against contemporary stultitia, so that one can think of other modes of existence and other possible worlds.
\end{abstract}

Keywords: denialism; conservatism; education.

Resumen

SENECA Y PAULO FREIRE: la lectura como equipo contra la stultitia contemporánea

Este artículo, que resulta del fragmento de una investigación arquegenealógica que investigó la clase desde la tradición grecorromana hasta prácticas pedagógicas innovadoras, busca reflexionar sobre la educación en la época contemporánea, a partir de las herramientas analíticas de lectura de Foucault como técnica del yo. Para ello, reúne la lectura como ejercicio espiritual practicado por el estoico Séneca y la lectura del mundo prevista por el educador brasileño Paulo Freire, en el año que celebra el centenario de su nacimiento. Este enfoque se abre como una posibilidad de confrontar formas de vida actuales basadas en la aceleración, la fragmentación y, recientemente, en ondas conservadoras y necrófilas, en las que la opinión ocupa el lugar de la ciencia y la palabra pierde su poder y valor. La lectura prolongada y atenta, por tanto, llega a constituirse 
como una forma de (re)existencia, formando un equipo contra la stultitia contemporánea, para que se pueda pensar en otros modos de existencia y otros mundos posibles.

Palabras clave: negacionismo; conservatismo; educación.

\title{
NOTAS INTRODUTÓRIAS
}

\begin{abstract}
Em países como o nosso, não casualmente, vemos sobreviver formas de terror corporal sob o influxo de uma desregulação neoconservadora, difundindo forças mórbidas de violência, ódio e horror, por meio de tecnologias necropolíticas que persistem incólumes e naturalizadas como parte do nosso repertório político.

(FREITAS, 2019, p. 21).
\end{abstract}

As profundas e rápidas mudanças que a sociedade contemporânea vem experimentando, especialmente a partir das últimas três décadas do século XX, concorrem para a produção de novos modos de subjetivação, em que a flexibilidade, a proatividade e o empresariamento de si tomam centralidade. O termo modernidade líquida, cunhado por Bauman (2001), não poderia ser mais apropriado para se referir ao modo de vida contemporâneo, que tem na impermanência, na instabilidade, na velocidade e na fluidez suas principais características. Segundo Bauman (2008, p. 161), o sucesso dos sujeitos pós-modernos "depende da velocidade com que conseguem se livrar de hábitos antigos, mais do que da rapidez com que adquirem novos". Esse hábito de viver sem hábitos, numa presentificação da vida, coloca o passado, a tradição e a contemplação em um nãolugar, ou em uma posição de esquecimento e de abandono. Lidar com o tempo tornou-se um dos grandes problemas humanos, no qual o tempo produtivo, o tempo do ócio e o tempo de vida refletem-se em soluções práticas ofertadas no mundo do consumo: gestão do tempo, qualidade de vida e postergação do envelhecimento são oferecidos insistentemente pelo mercado.

A essas formas de vida vêm se juntar, nas últimas décadas, movimentos conservadores, negacionistas e necrófilos, capilarizados por todo o planeta, e que, no Brasil conquistam legitimidade com a eleição presidencial de 2018 que coloca Jair Bolsonaro no centro decisório deste país. Atitudes desmesuradas com requintes de natureza facista alimentam-se das crises - de representatividade, ambientais, institucionais - e trazem à superfície problemas profundos e constitutivos da sociedade brasileira.

Com a crise pandêmica provocada pela Covid-19, tais problemas se intensificam e a desigualdade social é escancarada, mostrando-se como uma ferida aberta, nunca cicatrizada. Os povos indígenas, as comunidades quilombolas e LGBTQIA+ (lésbicas, gays, bissexuais, transexuais, travestis, transgêneros, queer, intersexuais, assexuais e mais) são os mais atingidos e têm sido alvo de perseguições e, em casos mais extremos, de extermínio.

As redes sociais tornam-se um espaço profícuo para o disseminamento de fake newss, onde a opinião toma o lugar das discussões aprofundadas, em que a ciência é colocada sob suspeição e o interesse pessoal se sobrepõe ao coletivo. Somam-se a isso alguns movimentos que buscam silenciar vozes que se colocam contrárias a esse modus operandi, e as várias tentativas de censura fulguram como uma ameaça constante. Poderíamos dizer que a estultícia se coloca como um grande perigo nestes tempos de fáceis opiniões e de tagarelices.

Nesse contexto nada promissor, em que há a "capitalização de todas as esferas da existência, em suma, um niilismo biopolítico", como argumenta Pelbart (2017, p. 271), pensar a educação 
torna-se um grande desafio. Desafio esse que nos provoca, a um só golpe, a buscar nas fissuras, rasgos, brechas, outras possibilidades de (re)existência.

No ano em que se celebra o centenário do nascimento de Paulo Freire, tomar a leitura praticada no estoicismo como um exercício para o cuidado de si e a leitura perspectivada pelo educador brasileiro pode ser uma forma de equipagem contra a estultícia contemporânea. A experimentação proposta neste artigo, que aproxima campos diversos de pensamento, é como "escrever - quando no ato de leitura alguma faísca de pensamento queima -, ao olhar, qualquer frase, qualquer parágrafo, qualquer anotação é registrar os pequenos e miúdos acontecimentos, que podem, em outros momentos, abrir infinitos campos de possibilidades futuros" (RODRIGUES, 2019, p. 50). Pois é justamente nas faíscas produzidas no encontro dessas miudezas que se pode pensar diferentemente do que se pensava e a agir, também, de outros modos.

Dessa forma, este artigo propõe-se a articular o pensamento de Paulo Freire e as práticas estoicas da cultura de si em Sêneca, a partir da temática da leitura, com base no recorte de uma pesquisa arquegenealógica que investigou a aula desde a tradição greco-romana à Contemporaneidade.

\section{DA ESTULTÍCIA COMO UM PERIGO, DA LEITURA COMO UM ANTÍDOTO}

Derivada da palavra latina stultus, aquele que não possui discernimento, a estultícia é "alguma coisa que a nada se fixa e que em nada se apraza" (FOUCAULT, 2006, p. 161). Apontada por Sêneca como um problema a ser combatido, a leitura funciona como uma espécie de antídoto capaz de tirar o sujeito desse estado de agitação da alma que não se atém à nada.

A leitura e a escrita, juntamente com outras práticas - memorizações, abstinências, silêncio, escuta do outro - desempenharam um importante papel nas tecnologias de sil e se encontram desde o chamado período arcaico grego (FOUCAULT, 2006), constituindo-se como um importante percurso de elaboração para tomar os discursos compreendidos como verdadeiros e transformá-los em princípios de ação, que é a askesis. A escrita, enquanto exercício de si atua convertendo a verdade em ethos, exercendo uma função etopoiéitica. Essa escrita etopoiéitica, diz Foucault (2006, p. 147), "tal como aparece em documentos dos séculos I e II, parece estar localizada no exterior das duas formas já conhecidas e utilizadas para outros fins: os hupomnêmata e a correspondência".

Os hupomnêmata eram uma espécie de bloco de notas, em que se podiam registrar citações, fragmentos, exemplos do que se ouvia ou lia; não se constituindo como lembrete para lapsos de memória, mas como um ferramental que dava suporte aos exercícios de leitura, releitura, meditação e conversa consigo e com os outros, que almejava a constituição de si. (FOUCAULT, 2006). Os hupomnêmata inserem-se nesse tensionamento de uma tradição que insiste, nas palavras de Foucault (2006, p. 149), "sob a chancela da antiguidade e da autoridade" e têm por propósito estabelecer uma relação do indivíduo consigo mesmo, "tão adequada e perfeita quanto possível", a partir dessa recolha de fragmentos operada pelo ensino, pela leitura e pela escuta.

A prática das notas, pois, vem a reforçar e sistematizar esses conjuntos de informações coletados nos diversos tipos de discursos (orais e escritos). Tal prática, no entanto, não busca armazenar os excertos em um arquivo-morto, mas fazer desse arquivo uma matéria viva para o

\footnotetext{
${ }^{1}$ Segundo Foucault (2004a, p. 323), as tecnologias do eu são aquelas tecnologias que permitem que os indivíduos efetuem "com seus próprios meios ou com a ajuda de outros, um certo número de operações em seus próprios corpos, almas, pensamentos, conduta e modo de ser, de modo a transformá-los com o objetivo de alcançar um certo estado de felicidade, pureza, sabedoria, perfeição ou imortalidade".
} 
pensamento e o exercício de si; um exercício, uma prática que se coloca em oposição à stultitia, que se caracteriza, segundo Foucault (2006, p. 150), "pela agitação da mente, pela instabilidade da atenção, pela mudança de opiniões e vontades, e consequentemente pela fragilidade diante de todos os acontecimentos que podem se produzir; caracteriza-se também pelo fato de dirigir a mente para o futuro", fazendo-a ansiosa e desejosa por novidades, impedindo-a, assim de concentrar-se "na posse de uma verdade adquirida". (FOUCAULT, 2006, p. 150).

Essa agitação da mente implica em uma abertura descomedida a tudo e a qualquer coisa, em que o stultus não reflete sobre o que lhe vem do mundo exterior, misturando-o com seus desejos, pensamentos, paixões, sem conseguir diferenciar, discernir tais elementos, não sendo "capaz de fazer a separação, a discriminatio entre o conteúdo destas representações [exteriores] e os elementos que chamaríamos, por assim dizer, subjetivos, que acabam por misturar-se com ele". (FOUCAULT, 2006, p. 162). O stultus também se caracteriza pela dispersão no tempo: sua atenção não se volta a nada, sua "existência passa", nos diz Foucault (2006, p. 162), "sem memória nem vontade [...] uma vontade que não é livre", mudando continuamente seu modo de viver, que "quer várias coisas ao mesmo tempo, coisas divergentes sem serem contraditórias. Ele não quer uma e absolutamente só uma. O stultus quer algo e ao mesmo tempo o lastima". Tais sintomas são muito fortes no presente, em que as verdades oscilam, e a palavra empenhada flutua entre uma afirmação e outra, perdendo sua força e seu valor. Frente à oferta interminável de estímulos, nos vemos encapsulados no excesso de escolhas e de modos de existência que tomamos para nós, oscilando entre as várias possibilidades que se abrem indistintamente. Possivelmente esse sintoma venha a explicar a atenção percebida pela sua falta, como um déficit, e não a partir de sua potência transformadora e criadora de mundos. Também vem a explicar o sucesso dos livros best sellers de autoajuda.

De qualquer maneira, percebe-se que os recursos empregados, quer seja com a literatura best seller, quer seja com a procura por modos alternativos de existência (vida em comunidades, práticas alimentares mais "saudáveis", exercícios físicos, auxílio psicológico, meditações, etc.), podem ser compreendidos como um sintoma de desconformidade com essa agitação na qual estamos mergulhados. Mesmo que não passe pela reflexão ou por um aprofundamento, isso nos diz algo. Um dos recursos empregados no presente e que são muito semelhantes aos hupomnêmata, são as agendas, os blocos de notas, os post-its, que utilizamos não somente para nos lembrarmos das tarefas e compromissos futuros, mas quando, de uma forma marginal, usamos para registrar aquilo que julgamos importante. Tais recursos pessoais, ou seja, quando livres da exposição, quando tomados como extensão da memória, quando guardados conosco e somente conosco, não deixam de ser um exercício, uma prática, um escape, mesmo que momentâneo, à essa agitação contemporânea. Nas aulas, do mesmo modo, quando propomos atividades de leitura e de escrita cujo objetivo não esteja atrelado à métrica, à comunicação, à gramática (que obviamente também é função da escola, mas não se esgota nisso), mas ao exercício de experimentação, promovemos algo semelhante.

Lutar contra a agitação da alma, contra os perigos dessa stultitia, constitui-se, na Antiguidade greco-romana, como um constante exercício. Daí advém a insistência de Sêneca, alega Foucault (2006), sobre a importância da leitura para o exercício de si, visto que ninguém consegue conduzir-se somente a partir do que existe em si próprio: a ajuda dos outros, quer como direção, quer como exemplo, é fundamental.

O mestre, nessa tradição, é o outro que zela pelo cuidado que o discípulo tem de si próprio; um cuidado que não encerra no indivíduo, mas que "se integra num tecido social e constitui um motor da ação política", como refere Gros (2013, p. 131), pois cuida-se de si para agir no mundo, não para escapar dele. (GROS, 2013). Esse cuidado não se dá de forma solitária e espontânea: ao 
contrário, o eu carece do outro para se constituir; não se trata de um cuidado egoísta que se volta para si e constrói seu mundo apartado dos demais, mas de uma "conquista difícil" (GROS, 2013, p. 132), uma atividade que "supõe sempre o acompanhamento de um mais velho e ele se distribui segundo atividades eminentemente sociais: conversações, troca de cartas, ensinamento e aprendizagem em escolas, formações individuais, etc.”. (GROS, 2013, p. 132). Um cuidado que tira o indivíduo do estado de stultitia, de relação com a não-vontade, ou com a vontade inerte; um cuidado que pressupõe o outro, não no sentido de "educare, mas de edúcere: estender a mão, fazer sair, conduzir para fora, que necessita da parada, do ócio. Vemos, pois, que de modo algum é um trabalho de instrução ou de educação no sentido tradicional do termo, de transmissão de um saber teórico ou uma habilidade". (FOUCAULT, 2006, p. 165). Trata-se de um cuidado ético consigo mesmo, que difere muito do que consideramos hoje bem-estar, exercícios físicos, alimentação saudável, e toda uma gama de práticas, preceitos e hábitos tidos como essenciais para uma vida feliz na atualidade, pois esses prescindem o caráter coletivo: voltam-se para cada um e encerram em si, excluindo o outro do processo. O sujeito contemporâneo passa a ser o princípio e o fim do cuidado de si, um deslocamento grande do que se vê na Antiguidade e que na modernidade sólida será denunciado como o outro da moral coletiva.

A lentidão, considerada de fundamental importância na tradição greco-romana e também na pastoral-cristã, se torna um problema a partir da Modernidade. Esse demorar-se, em que o tempo cronológico é suspenso, pois o foco atencional volta-se para a leitura, para a escrita, para o texto, constitui-se como um importante exercício de si.

A leitura, em Paulo Freire, também é perspectivada pelo aspecto formativo, que provoca mudanças no modo de ser do sujeito; nunca um sujeito individualizado e encapsulado em si mesmo, mas um sujeito em posição de abertura e voltado para o mundo comum. A importância atribuída por Freire à leitura, ao ato de ler, aponta que a "leitura da palavra não é apenas precedida pela leitura do mundo, mas por uma certa forma de 'escrevê-lo' ou de 'reescrevê-lo', quer dizer, de transformá-lo através de nossa prática consciente”. (FREIRE, 1989, p. 29).

Em seu belo texto A importância do ato de ler, Freire (1989), ao trazer argumentos que dão título à referida obra, esboça sua trajetória, num desenho em que a palavra assume o movimento por ele experimentado. Ao descrever sua singularidade, Freire permite que nós, outros, possamos sentir os aromas, perceber as variadas tonalidades de uma fruta-manga, ouvir o canto dos pássaros de sua infância em Recife. Também nos mostra instantes das suas aulas, enquanto professor de Língua Portuguesa, quando apresenta a leitura a seus alunos de maneira tão viva como "se ela fosse de agora e não de um ontem bem remoto, das vezes em que demorava na análise de textos de Gilberto Freyre, de Lins do Rego, de Graciliano Ramos, de Jorge Amado" (FREIRE, 1989, p. $27-$ 28).

Essa demora de Freire opera num movimento destoante do dessa velocidade na qual hoje mergulhamos, que não experimentamos e não damos a experimentar aos nossos alunos, porque estamos ocupados demais tentando atingir metas. Demora essa que descreve quando professor e aluno ou alfabetizador e alfabetizando - para usar ternos freirianos - tomam um objeto:

[...] sentem o objeto, percebem o objeto sentido e são capazes de expressar verbalmente o objeto sentido e percebido. Como eu, o analfabeto é capaz de sentir a caneta, de perceber a caneta e de dizer caneta. Eu, porém, sou capaz de não apenas sentir a caneta, de perceber a caneta, de dizer caneta, mas também de escrever caneta e, consequentemente, de ler caneta (FREIRE, 1989, p. 29). 
Nesse sentido, a alfabetização é tomada como um ato criativo, uma montagem do e no pensamento, como um gesto filosófico, político e artístico (RODRIGUES, 2020). A alfabetização, nas palavras de Freire (1989, p. 29), "é a criação ou a montagem da expressão escrita da expressão oral. Esta montagem não pode ser feita pelo educador para ou sobre o alfabetizando. Aí tem ele um momento de sua tarefa criadora". Esse momento único e singular de criação, em que a palavra opera na vida e no pensamento, promovendo mudança no modo de ser e de pensar o mundo, pode ser conjecturada como um antídoto contra a estultícia. A postura atentiva frente ao objeto, ao mundo, à palavra requer um tempo demorado, lento, exigindo certa lentidão, conforme a próxima seção.

\section{ESCUTAR OS MORTOS COM OS OLHOS: LEITURA COMO PRÁTICA DE LENTIDÃO}

Retirado en la paz de estos desiertos, con pocos, pero doctos libros juntos, vivo en conversación con los difuntos, y escucho con mis ojos a los muertos. (QUEVEDO, 2002, 36).

A epígrafe e o título desta seção trazem duas ideias importantes e que nos dão pistas sobre a potência da leitura demorada como uma possibilidade de equipagem à estultícia contemporânea: a leitura no encontro entre vivos e mortos e o forte traço da oralidade que ainda persiste na cultura ocidental, mesmo após o predomínio da escrita. Ambas as ideias atravessam a educação na Antiguidade e, também estão presentes na obra de Paulo Freire, em que a leitura de mundo precede à da palavra e a dialogicidade retoma práticas ancestrais. A primeira ideia diz respeito ao encontro entre gerações, cujas distintas temporalidades coexistem virtualmente no espaço físico da biblioteca e no ato da leitura. O espaço físico, nas palavras de Foucault (2009, p. 419), é heterotópico, pois opera em um "tempo que se acumula infinitamente, [...] não cessa de se acumular e de se encarapitar no cume de si mesmo". O ato da leitura diz respeito à sucessão de momentos que "coexistem: um, que é o presente e que não para de passar; o outro, que é o passado e que não para de ser, mas pelo qual todos os presentes passam". (DELEUZE, 1999, p. 45). Ao ler, a memória é invocada, e as experiências passadas de juntar as letras, formar palavras e frases são acionadas; emergem a um só tempo. À cada vez que lemos, a sucessividade de leituras torna-se presente, com sua singularidade própria, distinguindo-se "das precedentes e das subsequentes pela própria posição que ocupou no tempo; em suma, cada uma dessas leituras torna a passar diante de mim como um acontecimento determinado de minha história". (BERGSON, 1999, p. 85).

A ideia de tudo acumular, nos diz Foucault (2009, p. 419), "de constituir uma espécie de arquivo geral, a vontade de encerrar em um lugar todos os tempos, todas as épocas, todas as formas, todos os gostos, a ideia de constituir um lugar de todos os tempos que esteja ele próprio fora do tempo, e inacessível à sua agressão" é algo recente na história humana, próprio da "cultura ocidental do século XIX”. (FOUCAULT, 2009, p. 419). Larrosa (2007, p. 134) diz que a "crise da formação humanista e o triunfo da educação técnico-científica supuseram a abolição da biblioteca como o espaço privilegiado da formação". 
O outro aspecto mencionado - a oralidade - se mantém presente na relação pedagógica mesmo após o predomínio da escrita, conforme já apontado ${ }^{2}$, em que esta última vai se tornar, paulatinamente, o epicentro educacional. "A vista substituiu o ouvido como órgão de perceção, receção e de organização da vida social" (Ó, 2019, p. 124), não obstante algumas práticas orais ainda persistem, como nas conferências, debates, diálogos e leituras orais. Todas essas práticas evidenciam uma preocupação com a palavra e com o exercício do pensamento, constituindo-se uma importante tecnologia de si.

$\mathrm{Na}$ Contemporaneidade, a leitura tende a se restringir à compreensão de um texto, à uma atitude de recognição, de deciframento de código e de adequação interpretativa, em que pouco espaço sobra para o pensamento e para a inventividade, pois a informação é mais importante do que a formação. E é precisamente sobre essa questão que este artigo se debruça: de que maneira a leitura opera na constituição de modos de existência? Como esse deslocamento da formação à informação pode nos ajudar a conjecturar outras possibilidades de relação com o texto? Qual a relação entre a leitura praticada na Antiguidade com a leitura de mundo proposta por Freire e como essa relação pode se constituir como um enfrentamento à estultícia contemporânea?

As mudanças que têm se dado nas práticas de leitura na aula ao longo da tradição educacional do Ocidente dizem respeito a vários aspectos, aqui podendo citar dois: o suporte de inscrição das tabuinhas de argila utilizadas pelos mesopotâmicos até as telas de computadores e demais dispositivos móveis e a relação com o livro e com as formas de ler. Segundo Chartier, nem mesmo as grandes mudanças que se deram na relação com o livro e a leitura a partir da prensa de Gutenberg aproximam-se das mudanças a partir do livro eletrônico: "ante o monitor, a leitura é uma leitura descontínua, segmentada, mais ligada ao fragmento do que à totalidade". (CHARTIER, 2010, p. 9). O escritor Nicholas Carr, na obra A geração superficial: o que a Internet está fazendo com nossos cérebros, também faz importantes problematizações a respeito das diversas mudanças provocadas pelo uso da internet, em que argumenta que nossa leitura se tornou superficial ao saltarmos de um texto a outro, de um link a outro, de uma janela a outra, sem nos determos atentamente ao conteúdo do que é lido.

Dessa forma, é importante insistir nesta grande mudança, que é a fragmentação, a leitura segmentada, apartada do conjunto e que convida o leitor a uma relação de leitura saltitante e dispersa, promovendo novas maneiras de relação com o texto e, portanto, com o estudo. Cabe salientar que o esforço aqui empreendido não diz respeito ao julgamento dessas práticas no presente, mas a um exercício de pensamento sobre o aspecto formativo da leitura no campo educacional. Poderíamos dizer, no presente, de leituras operadas em super velocidade, apartadas do ensino, da formação e da constituição de relação com um patrimônio cultural, porque estariam mais voltadas a dar conta de atividades consideradas úteis ao capitalismo contemporâneo, traduzindo-se em leituras pragmáticas e de fácil e imediata aplicação. Ao mesmo tempo, o excesso de opiniões vazias que circulam, especialmente nas mídias sociais, atualmente, acaba por provocar um esvaziamento da própria palavra.

A tendência crescente observada nas últimas décadas de estudar as obras em fragmentos ou a partir de comentaristas em detrimento dos textos originais está articulada ao tempo, cada vez mais escasso, que encontramos hoje, para o aprofundamento que a leitura de obras na sua íntegra tomaria: um tempo que é preenchido por uma série de outros estudos - avaliados mais urgentes que se somam, cada vez mais, aos currículos escolares e universitários. Nuccio Ordine (2016)

\footnotetext{
${ }^{2}$ É preciso lembrar que o processo de alfabetização de um contingente maior de pessoas que não apenas as econômicas ou socialmente favorecidas é algo bem recente na história da educação ocidental, e no Brasil isso toma concretude a partir da Constituição de 1988 e da Lei de Diretrizes e Bases da Educação Nacional 9194/96, de 1996.
} 
aponta que os alunos têm sido cada vez mais encorajados a utilizarem-se de fragmentos em detrimento da leitura aprofundada de uma obra clássica. Isso ocorre não somente em função do tempo, mas do esforço linguístico que tal leitura demandaria.

Ramos do Ó (2019), ao dedicar-se às teorias da educação e da aprendizagem do humanismo italiano, aponta a importância atribuída à leitura dos textos clássicos na educação renascentista. Segundo o autor, ao aluno desse período não era proposto um esgotamento interpretativo da totalidade de uma obra ou mesmo o pensamento de determinado autor, mas "perceber como uma ideia ou um nome se exprimiam no interior de uma ampla série discursiva, fazendo ressoar esta ou aquela temática, este ou aquele tópico”. (Ó, 2019, p. 182).

Ao longo da Antiguidade encontramos inúmeros exercícios voltados para a constituição de uma bela existência, ligado a um modo filosófico de vida, que exige vigorosa dedicação, operado por um conjunto de práticas, de estudos e de exercícios que abrangem todos os aspectos da vida, cuja intenção é formar os espíritos. A leitura se insere nesse quadro de exercícios, aos quais Pierre Hadot $(2014,2014 a)$ chama de exercicios espirituais.

Os mestres da Antiguidade recomendavam a seus alunos que a leitura iniciasse por um número pequeno de autores e obras direcionadas a pequenos trechos para a posterior escolha das partes significativas; prática essa comum ao longo da tradição greco-romana, (FOUCAULT, 2006). Essa prática almejava buscar aquilo que viria a promover a meditação, a reflexão. Nas escolas romanas, o aprendizado da leitura se dava pelo estudo de textos poéticos que se repetem por diversas gerações; uma tradição que selecionava a galeria de excertos e que constituíam, nas palavras de Marrou (1973, p. 241), "a base da erudição poética comum a todos os homens cultos”.

A leitura, ainda nessa tradição, se dava em voz alta, e isso perdurou até o Baixo Império: somente bem mais tarde o hábito de uma leitura silenciosa se faz necessário. Os alunos recitavam os textos, passando, posteriormente, a memorizá-los: Marrou (1973) argumenta que ao comparar um manual escolar do final do século III a.C. com um caderno copta do IV século de nossa era, surpreende-se com a similitude metodológica adotada num período temporal em que mais de quinhentos anos os separam. A escolha metodológica de utilização de fragmentos, também está ligada à dificuldade de manuseio do papiro (cuja extensão atingia cerca de $2 \mathrm{~m} 90 \mathrm{~cm}$ ) pelas crianças, que tinham que desenrolar e enrolar ao mesmo tempo nas hastes de madeira coladas nas extremidades, pois o códex surgiu no período Imperial romano com o intuito de comportar obras volumosas. (MARROU, 1973).

A prática de selecionar excertos buscava, como dito anteriormente, promover a reflexão, "propiciar uma ocasião de meditação" (FOUCAULT, 2006, p. 428). Encontramos, em Sêneca, uma quantidade de fragmentos de textos colecionados, aos quais chama de máximas, para que pudesse ofertá-las a Lucílio, como a Carta 13, em que diz: "é tempo de terminar esta carta. Só falta imprimir nela o sinete, isto é, citar alguma máxima importante sobre a qual medites" (2018, p. 43); ou a Carta 78 (p. 337), em que aconselha "vai-te entretendo com estas meditações, mas não deixes de arranjar tempo para me escrever".

Aqui, o texto a ser enviado não tinha o caráter instrumental de aperfeiçoar a escrita, a língua, ou qual fosse o conteńdo ao qual pudesse ser aproveitado enquanto matéria de estudo, senão para fazer com que Lucílio meditasse. Esse caráter pedagógico, que se está a oferecer à conta-gotas, periodicamente, proporciona ao aluno um exercitar-se constante; pensar a partir de um fragmento para fazer outro de si próprio, fazer "fluir pequenos fragmentos de textos criando nexos de sentidos", como diz Rodrigues (2020, p. 181). Pois é justamente dos nexos de sentido que se tratavam esses excertos, essas máximas: operar, por meio de uma faísca no pensamento provocada por algumas breves palavras, uma modificação interna, uma mudança no pensamento e na atitude, em que o mestre exercia o papel colecionador. 
Essa prática de catar coisas que estão espalhadas pelo mundo, transformando-as em algo imprevisto, dando a elas um novo sentido ou significado, é bastante antiga. O colecionador é alguém que junta coisinhas, que vão de botões a frases; é aquele que "tira o objeto de sua relação funcional, cria outros sentidos para seu uso e desenvolve um ordenamento e um esquema de leitura". (RODRIGUES, 2002, p. 77). Walter Benjamin (2009, p. 239) diz ser "decisivo na arte de colecionar que o objeto seja desligado de todas as suas funções primitivas, a fim de travar relação mais íntima que se pode imaginar com aquilo que lhe é semelhante. Essa relação é diametralmente oposta à utilidade e situa-se sob a categoria singular da completude”. Uma completude que se dá na relação entre o colecionador e suas coisinhas, seus achados que perdem a função original para o qual foram feitos.

Algo muito semelhante acontece na leitura, quando tomamos as palavras, frases, fragmentos, os retiramos de seu lugar e funções originais e os colocamos em um outro contexto, cenário, dando-lhes a possibilidade de um outro nascimento. Rodrigues $(2020$, p. 50) fala sobre seu processo de leitura e coleção de citações. Diz ele: “eu sempre leio, qualquer livro, com um lápis na mão, como uma forma de puxar o pensamento pela ponta do lápis. Por vezes releio várias vezes a mesma passagem até que a palavra, a frase faça algum sentido. Vou guardando-as, tenho uma coleção de citações literárias e filosóficas".

Colecionar, pois, os excertos, as frases, os fragmentos recolhidos nas leituras, num tempoatenção, em que a cada frase se tem de retornar, ler outras tantas vezes, riscar, como quem puxa o pensamento com a ponta do lápis, extraindo dali o que comporá sua coleção: esse é o trabalho do mestre na apresentação do mundo e na condução das condutas no tempo-atenção do estudo na aula; não se trata de esgotar a leitura de um texto, mas tomar aquilo que será importante em sua vida. Percebese que a intenção da leitura é tomar o texto como um "exercício pelo qual o sujeito se põe, pelo pensamento em uma determinada situação [...] fictícia na qual se experimenta a si mesmo, é isto que explica que a leitura filosófica seja - se não totalmente, ao menos em boa parte - indiferente ao autor, indiferente ao contexto da frase ou da sentença" (FOUCAULT, 2006, p. 430), e que não está apartada da escrita, segundo Sêneca. Não se trata, diz Foucault (2006), da relação do sujeito com seu pensamento, mas de colocá-lo na experiência por meio do pensamento.

Outra prática de leitura recomendada pelos estóicos era a análise aprofundada de determinada obra ou autor para que os alunos pudessem construir um bloco de sentido. Não obstante as diferenças metodológicas, o propósito era o mesmo: fazer da leitura uma equipagem à vida. Sêneca diz da importância de ler uma quantidade menor de autores ao invés de ler grande quantidade, fazendo uma analogia com a alimentação, pois quem come demais fica com o estômago embotado. Se refere aqui aos excessos, que ao invés de contribuírem para o crescimento de seu discípulo, somente o dispersaria. Orienta a Lucílio que escolha algum trecho que lhe sirva de alimento para a meditação.

Demasiada abundância de livros é fonte de dispersão; assim como não poderás ler tudo quanto possuis, contenta-te em possuir apenas o que podes ler. Dirás tu: "Mas sinto vontade de folhear ora este livro, ora aquele." Provar muita coisa é sintoma de estômago embotado; quando são muitos e variados os pratos, só fazem mal em vez de alimentar. Lê, portanto, constantemente autores de confiança e quando sentires vontade de passar a outros, regressa aos primeiros. Reflecte todos os dias em qualquer texto que te auxilie a encarar a indigência, a morte ou qualquer outra calamidade; quando tiveres percorrido diversos textos, escolhe um passo que alimente a tua meditação durante o dia. (SÉNECA, 2018, p. 3). 
A analogia com o processo de digestão empregado por Sêneca remete à ideia de demora, de lentidão, necessária para o processo formativo de Lucílio. É essa demora que possibilita a articulação entre o texto e a existência, em que a palavra provoca a mudança no modo de ser daquele que lê. Isso exige tempo. Sêneca, em outra carta, utiliza outra metáfora - a das abelhas - para apontar a importância da discriminação das partes no processo de leitura, de forma a conseguir melhor absorvê-las e mantê-las na memória, argumentando que o que resultar dessa coleta será um produto totalmente novo, pois embora conserve as partes, elas se metamorfosearão numa outra coisa. Percebe-se aqui a importância do método de leitura que atravessa a aula na tradição grecoromana do cuidado de si e que busca provocar a mudança no modo de ser do aluno, conforme apontado anteriormente: uma leitura atentiva para consigo e com a matéria.

[...] devemos imitar as abelhas, discriminar os elementos colhidos nas diversas leituras (pois a memória conserva-os melhor assim discriminados), e depois, aplicando-lhes toda a atenção, todas as faculdades da nossa inteligência, transformar num produto de sabor individual todos os vários sucos coligidos de modo a que, mesmo quando é visível a fonte donde cada elemento provém, ainda assim resulte um produto diferente daquele onde se inspirou. (SÉNECA, 2018, p. 381).

Paulo Freire, cerca de 20 séculos depois, retoma essa ideia da leitura atenta, do estudo aprofundado, se colocando adverso àquilo que hoje nos é tão comum, que é a leitura apressada, sem a ruminação devida, sem o tempo de pausa, ou de suspensão para que as palavras produzam algum sentido naquele que lê: "creio que muito de nossa insistência, enquanto professoras e professores, em que os estudantes 'leiam', num semestre, um sem-número de capítulos de livros, reside na compreensão errônea que às vezes temos do ato de ler" (FREIRE, 1989, p. 26). Para Freire, tal insistência, por parte dos professores, provoca uma devoração e não a compreensão do que é lido ou estudado, revelando uma "visão mágica da palavra escrita. Visão que urge ser superada. A mesma, ainda que encarnada desde outro ângulo, que se encontra, por exemplo, em quem escreve, quando identifica a possível qualidade de seu trabalho, ou não, com a quantidade de páginas escritas" (FREIRE, 1989, p. 27). Essa crítica de Freire à magicização da palavra não propõe o rompimento com os textos clássicos, e tampouco demonstra uma postura leviana de sua parte quanto "à necessidade que temos, educadores e educandos, de ler, sempre e seriamente, os clássicos neste ou naquele campo do saber, de nos adentrarmos nos textos, de criar uma disciplina intelectual, sem a qual inviabilizamos a nossa prática enquanto professores e estudantes". (FREIRE, 1989, p. 27).

A preocupação explicitada por Freire é bastante pertinente, em especial se a tomamos neste tempo em que vivemos, marcados pela aceleração e pelo rompimento com o que foi historicamente produzido pela humanidade. Isso nos aponta para uma atenção à memória e ao compromisso e responsabilidade de apresentação do mundo, em que a leitura do texto clássico opera como uma ponte entre o passado e o presente, pois o clássico é "[...] aquilo que persiste como rumor mesmo onde predomina a atualidade mais incompatível”. (CALVINO, 1993, p. 14). Clássicos também são aqueles autores que "[...] mesmo vinculados de uma maneira mais incisiva a uma área específica do conhecimento, produzem algo tão significativo que conseguem extrapolar as suas fronteiras tradicionais. Por este motivo, costumamos tratá-los como clássicos". (DEINA, 2018, p. 3). Calvino (1993, p. 14), em continuação à ideia anunciada, argumenta que a nós "[...] resta o fato de que ler os clássicos parece estar em contradição com nosso ritmo de vida, que não conhece os tempos longos, o respiro do otium humanista". Nesse mesmo sentido, Ordine (2016) aponta que não há como pensar a educação sem a leitura dos clássicos. Talvez seja propositada, então, a aparente 
"antagônica" imagem de que a inovação se opõe, como quer crer o senso comum, ao clássico, assim como o ensino aparenta se opor à educação. E isso vem ao encontro do propósito deste artigo, que se põe a pensar na leitura como uma equipagem contra a estultícia contemporânea.

Ao observarmos algumas tendências educacionais atuais, cujas propostas pedagógicas buscam se adequar à velocidade imposta pelo mercado, em que as tecnologias e a inovação tomam centralidade no processo pedagógico, e importantes disciplinas, como a Filosofia, por exemplo, são retiradas dos currículos escolares, tomar algumas práticas de leitura apresenta-se como uma possibilidade de (re)existência. $\mathrm{O}$ insistente rompimento com a tradição, a que assistimos nas últimas décadas, nesse abandono do passado, também aponta um rompimento com o futuro, evidenciando uma presentificação da vida, promovendo uma existência destituída de vida, ou, utilizando os termos de Agamben (2007), uma vida nua.

\section{CONSIDERAÇÕES FINAIS}

Chegar a ser o que se é pressupõe que se tem uma suspeita minima do que se é. (NIETZSCHE, 2008, p. 38).

A provocação nietzschiana de como nos tornamos o que somos é deveras pertinente, sobretudo quando falamos desde o campo da educação, em que as tecnologias do eu insistem em tomar corpos, pensamentos e almas sob a perspectiva pragmática, utilitária e individualista. A perplexidade com que assistimos, nas últimas décadas e especialmente nos últimos anos, sobretudo no Brasil, a inúmeras atitudes desmesuradas, aparentemente inconsequentes, a desfilarem no terreno político, em que a estultícia se evidencia com bastante nitidez, pensar sobre o que nos trouxe até aqui, ou como nos tornamos o que somos, possa apontar alguns caminhos para que possamos, com a mesma intensidade, ousar caminhar em outras direções.

Em tempos em que a palavra perde seu valor formativo para as fáceis opiniões, em que a doxa toma a cena e coloca a estultícia em posição protagonista, é urgente que exercitemos outras possibilidades de (re)existência. Em tempos em que a leitura é tomada desde uma visão pragmática, algo que tem fim em si, uma habilidade a ser adquirida, posta a serviço de um resultado, subtraindose dela toda sua potência, conversar com a tradição pode nos ajudar a compreender em como nos tornamos o que somos, como sugere Nietzsche.

Tomar a leitura para além de uma relação comunicacional, seria valer-se da linguagem "como possibilidade de transgressão, contestação da cultura na subversão mesma dos códigos da língua" (SCHULER, 2017, p. 239) para enfrentar os grandes desafios contemporâneos, em que a estultícia assume destaque. Transgredir os códigos num movimento maquínico que toma a palavra desde sua força (trans)formadora quando se pensa a formação humana é permitir-se ousar, arriscarse em alguma coisa ainda não experimentada, provocando que algo outro possa surgir. $\mathrm{O}$ texto, nessa perspectiva, torna-se múltiplo, ou tomando de empréstimo as palavras de Barthes (2004, p. 70) é "Plural", não somente por apresentar múltiplos sentidos, mas porque faz "o próprio plural do sentido: um plural irredutível (e não apenas aceitável). O Texto não é coexistência de sentidos, mas passagem, travessia; não pode, pois, depender de uma interpretação, ainda que liberal, mas de uma explosão, de uma disseminação". Isso se articula à ideia de leitura em Sêneca e em Paulo Freire, em que o texto tomado como travessia traz o movimento, o deslocamento que opera no modo como percebemos e vivemos no mundo, "em que a palavra dita flui do mundo mesmo através da leitura que dele fazemos”. (FREIRE, 1989, p. 29). Nesse sentido, a educação pode ser compreendida como uma educação pelo sonho, visto que "nutre e nutre-se da função social ao 
considerar cada sujeito em suas constelações, fases e passagens da vida. Circularmente, o pensamento sonha, livre da dicotomia dia e noite". (REIS; CORAZZA, 2021, p. 456).

O convite proposto neste artigo, que estabeleceu a conversação entre autores distantes, num diálogo que buscou exercitar o pensamento para além de enquadramentos epistemológicos, tomando a leitura desde sua potência criadora e transformadora, pode contribuir como uma equipagem contra a estultícia. Convite que busca, na leitura dos clássicos, sopros inspiradores e que nos convocam a conjecturar outras e múltiplas formas de existir e outros mundos possíveis, neste tempo em que nos cabe viver e sonhar.

\section{REFERÊNCIAS}

AGAMBEN, Giorgio. Homo Sacer: o poder soberano e a vida nua. Belo Horizonte: Ed. da UFMG, 2007.

BARTHES, Roland. O rumor da lingua. São Paulo: Martins Fontes, 2004.

BAUMAN, Zygmunt. Modernidade Líquida. São Paulo, Jorge Zahar Editor Ltda. 2001.

BERGSON, Henri. Matéria e memória: ensaio sobre a relação do corpo com o espírito. 2 ed. São Paulo: Martins Fontes, 1999.

CALVINO, Italo. Por que ler os clássicos. São Paulo: Companhia das Letras, 1993.

CARR, Nicholas. A geração superficial: o que a Internet está fazendo com nossos cérebros.

Tradução de Mônica Gagliotti Fortunato Friaça. Rio de Janeiro: Agir, 2011.

CHARTIER, Roger. Escutar os mortos com os olhos. Estudos Avançados, v. 24, n. 69, p. 6-30, 1 jan. 2010.

DEINA, Wanderley José. A crise na Educação, 60 anos depois: apontamentos sobre a crise educacional moderna no quadro teórico da A condição humana, de Hanna Arendt. Educaşão em Revista, Belo Horizonte, v. 34, 2018, p. 1-29.

DELEUZE, Gilles. Bergsonismo. São Paulo: Ed. 34, 1999.

FOUCAULT, Michel. Tecnologias de si. São Paulo: PUC. n. 6, 2004a. p. 321-360.

FOUCAULT, Michel. A hermenêutica do sujeito. 2 ed. São Paulo: Martins Fontes, 2006.

FOUCAULT. Michel. Estética: literatura e pintura, música e cinema. Rio de Janeiro: Forense Universitária, 2009.

FREIRE, Paulo. Pedagogia do oprimido. Rio de Janeiro, Paz e Terra, 1983.

FREIRE, Paulo. A importância do ato de ler. em três artigos que se completam. São Paulo: Autores Associados: Cortez, 1989.

FREITAS, Alexandre Simão de. Geontologia e as artes neoliberais de governo: educar os corpos para além do imaginário do carbono. Pro-Posições, Campinas, SP, v. 30, p. 1-21, 2019.

GROS, Frédéric. O cuidado de si em Michel Foucault. In: RAGO, Margareth; VEIGA-NETO, Alfredo. (orgs.). Figuras de Foucault. Belo Horizonte: Autêntica, 2013. 3. ed. p. 127-138.

HADOT, Pierre. O que é a filosofia antiga? São Paulo: Loyola, 2014.

HADOT, Pierre. Exercícios espirituais e filosofia antiga. São Paulo: É Realizações, 2014a.

LARROSA, Jorge. Literatura, experiência e formação. In: COSTA, Marisa Vorraber. (org.).

Caminhos Investigativos I: Novos olhares na pesquisa em educação. Rio de Janeiro: Lamparina, 2007, p. 129-156. 
MARROU, Henri Irénée. História da Educação na Antiguidade. São Paulo: Editora da Universidade de São Paulo, 1973.

NIETZSCHE, Friedrich. Ecce Homo: como se chega a ser o que se é. Trad. Artur Morão. Covilhã: Universidade da Beira Interior, 2008.

Ó, Jorge Manuel Ramos do. Fažer a mão: por uma escrita inventiva na universidade. Lisboa:

Edições do Saguão, 2019.

ORDINE, Nuccio. A utilidade do inútil. Rio de Janeiro: Zahar, 2016.

PELBART, Peter Pál. O que é o contemporâneo? Eikasia: Revista de Filosofia , v. 75, p. 267-277, 2017. Oviedo - España, 2017.

QUEVEDO, Francisco de. Antología poética. Alicante: Biblioteca Virtual Miguel de Cervantes, 2002.

REIS, Marina dos; CORAZZA, Sandra Mara. Sonhografias em educação. Revista Teias, [S.l.], v. 22, n. 66, p. 446-458, ago. 2021.

RODRIGUES, Elisandro. Montagem: por uma escrita em educação. 464 f. (Tese). Programa de Pós-graduação em Educação, (Doutorado em Educação), Unisinos, São Leopoldo, 2020.

SCHULER, Betina. Escrita escolar, ficção e modos de subjetivação. Educação Unisinos, v. 21, n. 2, p. 233-242, ago. 2017.

SÉNECA, Lúcio Aneu. Cartas a Lucilio. Lisboa: Calouste Gulbenkian, 2018.

Submissão em agosto de2021

Aprovação em outubro de2021

\section{Informações da autora}

Maria Alice Gouvêa Campesato

Unisinos; Prefeitura Municipal de Porto Alegre

E-mail: mcampesato@yahoo.com.br

ORCID: https://orcid.org/0000-0002-1965-9564 